\title{
Meta-analysis of phase III trials of docetaxel alone or in combination with chemotherapy in metastatic breast cancer
}

\author{
Maurizio Belfiglio $\cdot$ Caterina Fanizza $\cdot$ Nicola Tinari $\cdot$ Corrado Ficorella $\cdot$ \\ Stefano Iacobelli • Clara Natoli • Consorzio Interuniversitario Nazionale per la Bio-Oncologia (CINBO)
}

Received: 20 June 2011 / Accepted: 3 November 2011/Published online: 18 November 2011

(C) The Author(s) 2011. This article is published with open access at Springerlink.com

\begin{abstract}
Purpose Whether combination chemotherapy offers an advantage over sequential therapy in metastatic breast cancer (MBC) is still an unsettled issue. Polychemotherapy regimens containing taxanes has been shown to increase overall survival (OS), time to tumor progression (TTP), and overall response rate (ORR) when compared with regimens that did not contain a taxanes, while taxane-based doublets have a statistically significant benefit over single-agent taxane only for progression-free survival. However, the term "taxanes" generally includes both paclitaxel and docetaxel, drugs with different clinical activity. Aim of this work is to compare OS, TTP, and ORR in patients with MBC receiving docetaxel alone or in combination with chemotherapy using a formal meta-analysis.

Methods We performed a systematic review of all published trials comparing docetaxel alone or in combination with other chemotherapeutic agents in MBC.

Results Three randomized clinical trials including 1,313 patients were retrieved. A significant reduction of risk ratio was found in TTP $(P \leq 0.0001)$ but not in OS $(P=0.48)$ or ORR $(P=0.10)$ for patients treated with a chemotherapy
\end{abstract}

\footnotetext{
M. Belfiglio $(\square) \cdot$ C. Fanizza

Department of Clinical Pharmacology and Epidemiology, Consorzio Mario Negri Sud, Via Nazionale 8/A,

Santa Maria Imbaro, Chieti, Italy

e-mail: belfiglio@negrisud.it

N. Tinari $\cdot$ S. Iacobelli $\cdot$ C. Natoli

Unit of Medical Oncology, Department of Oncology and Experimental Medicine and CeSI, Fondazione 'G. D' Annunzio', University of Chieti-Pescara, 66100 Chieti, Italy

C. Ficorella

Department of Experimental Medicine, University of L'Aquila, 67100 L'Aquila, Italy
}

agent plus docetaxel compared with docetaxel alone. Treatment with docetaxel alone is associated with a lower incidence of grade 3 diarrhea and stomatitis (diarrhea, $P=0.011$; stomatitis, $P=0.0004$ ).

Conclusion Combination chemotherapy regimens with docetaxel show a statistically significant advantage for TTP, but not for OS and ORR in MBC. This review confirms that it is unlikely that any single agent or combination chemotherapy regimen will emerge as superior in $\mathrm{MBC}$, due to its heterogeneous nature.

Keywords Metastatic breast cancer - Meta-analysis . Docetaxel · Taxanes

\section{Introduction}

Metastatic breast cancer (MBC) is still an incurable disease, even if mortality has been decreasing steadily in the developed countries in the last 10 years (Jemal et al. 2010a, b). Approximately $6 \%$ of women with breast cancer are metastatic at diagnosis and $\sim 20 \%$ of patients initially diagnosed with localized disease will develop MBC (Brewster et al. 2008). Goals of therapy include prolongation of survival, delay of disease progression, and palliation of symptoms.

The medical treatment of MBC includes a wide range of options (chemotherapy, endocrine treatment, and therapy with monoclonal antibodies and tyrosine kinase inhibitors) with chemotherapy still representing the mainstay of treatment (Force 2007; Beslija et al. 2009).

Whether combination chemotherapy offers an advantage over sequential therapy for the management of MBC is still an unsettled issue (Cardoso et al. 2009, 2010; Kostler et al. 2010). A recent review of trials using combination versus 
single-agent chemotherapy in MBC (Carrick et al. 2009) shows a significant advantage of polychemotherapy in terms of overall response rate (ORR), progression-free survival (PFS), and overall survival (OS), but these data are hampered by the use, in several cases, of single agents (such as mitoxantrone, lomustine, ifosamide, etc.) that are no longer considered as standard treatments. Therefore, these findings may not be applicable to more recent active single agents such as taxanes, currently considered as the cornerstones of MBC treatment (Radaideh and Sledge 2008). Also the effects of adding one or more chemotherapy drugs at first-line regimen of at least two chemotherapy drugs have been reported to have a statistically significant advantage for ORR, but no differences in OS or time to tumor progression (TTP) and the positive effect being associated with increased toxicity (Butters et al. 2010).

Polychemotherapy regimens containing taxanes have been shown to increase OS, TTP, and ORR when compared with regimens that did not contain a taxane (Ghersi et al. $2005 \mathrm{a}, \mathrm{b}$ ), even if taxanes in combination with anthracyclines did not show an OS benefit over single-agent taxanes, when used as first-line treatment of MBC (PiccartGebhart et al. 2008). The clinical activity of taxane monotherapy against taxanes in combination regimens has been extensively investigated (Cardoso et al. 2009). A recent meta-analysis has shown a statistically significant benefit in favor of taxane-based (paclitaxel or docetaxel) doublets over single-agent taxane only for PFS and a non significant trend toward an improved ORR in patients with advanced breast cancer and prior anthracycline treatment (Xu et al. 2011).

A major problem in interpreting these data is related to the fact that the term "taxanes" generally includes paclitaxel, docetaxel, and nanoparticle albumin-bound paclitaxel (nab-paclitaxel), although they differ with respect to pharmacokinetic profile, toxicity, and clinical activity (Ghersi et al. 2005b; Rosati et al. 2011; Ardavanis et al. 2008; Mukai et al. 2010; Burstein et al. 2007; Jones et al. 2005). Moreover, many published trials allow to use indifferently paclitaxel or docetaxel in one arm of treatment (Rosati et al. 2011; Ardavanis et al. 2008; Mukai et al. 2010; Burstein et al. 2007) with docetaxel appearing superior to paclitaxel in most trials doing a direct comparison (Jones et al. 2005; Vu et al. 2008; Lin et al. 2007).

The aim of this work is to compare OS, TTP, and ORR in patients with $\mathrm{MBC}$ receiving docetaxel alone or docetaxel in combination with other chemotherapeutic agents using a formal meta-analysis. We performed a comprehensive systematic review of all randomized phase III trials that compared docetaxel alone or in combination with polychemotherapy without the addition of biologics (such as trastuzumab or bevacizumab) in MBC. Three trials corresponded to the above-mentioned characteristics
(O’Shaughnessy et al. 2002; Pacilio et al. 2006; Sparano et al. 2009).

\section{Methods}

Data sources and selection criteria

The goal of this study was to determine whether addition of chemotherapy agent(s) to docetaxel monotherapy improves outcome of MBC. We included prospective, randomized, controlled open or blinded trials of participants with metastatic breast cancer.

We excluded non-randomized trials and quasi-randomized trials with alternate allocation of patients; data on other malignancies; trials comparing radiotherapy, hormonal and gene therapy; trials with biological agents; arms comparing local routes of administration; and comparisons of chemotherapy against no treatment (best supportive care).

The outcomes of interest were OS, TTP, ORR, and toxicity

Using the terms related to MBC treated with docetaxel and a filter highly sensitive for randomized controlled trials only, we searched Medline, Cochrane Central, EmBase, and Cancer Lit for articles published in English from January 2000, to December 2010. In addition, we integrated the electronic search with published abstracts from conference proceedings. Two authors independently reviewed results of the search strategies and identified eligible trials; data extraction was done independently by the same authors using a predefined form. Information was collected on study design, study sample, characteristic of the populations, interventions, line of chemotherapy, methodological quality of the trials, and outcomes (OS, TTP, and ORR).

For each trial, we recorded median survival and number of deaths in each arm, wherever available, and whether the trial noted a statistically significant difference in survival between the compared arms (two tailed $P<0.05$ )

Discrepancies between the two reviewers were resolved through discussion and consensus, with an arbitrator.

\section{Quality assessment of methods}

Methodological quality of included randomized controlled trials was assessed by several domains: allocation concealment (considered "adequate" if randomization method was described such that it would not allow the investigator or participant to know or influence the intervention group before eligible participants had entered the study; "unclear" if randomization was stated, but no information on method used was available; "inadequate" when the 
study used a method of randomization such as alternation, medical record numbers, date of birth, or unsealed envelopes, or if any information in the study indicated that investigators or participants could influence allocation to the experimental or control group); blinding of investigators, participants, and outcome assessors; use of intention to treat analysis; completeness of follow-up.

Discrepancies in data extraction between the two reviewers were resolved by discussion and consensus, with an arbitrator.

\section{Statistical analysis}

We compared treatments using relative risks with $95 \%$ confidence intervals. Heterogeneity between studies was assessed with the Cochran's Q and the $\mathrm{I}^{2}$ statistics (Higgins et al. 2003). The pooled risk ratio (RR) estimate was calculated using random-effect model (van Houwelingen et al. 2002). To statistically assess any publication bias, we used the Egger regression asymmetric test, with a .05 level of significance (Egger et al. 1997). The influence of potential sources of heterogeneity on treatment effects was explored by subgroup analysis. The following characteristics of the population, intervention, and methodological quality of the trials were defined a priori as potential effect modifiers: duration of treatment, allocation concealment, and compliance with treatment. Analyses were carried out using a macro routine written in SAS Language (Release 9.1, 2002-2003).

\section{Results}

Study characteristics

Of 217 potentially eligible studies identified by the search strategy, 164 were excluded because they tested an intervention other than docetaxel monotherapy versus docetaxel in combination with chemotherapy and 50 because they were not randomized controlled trials, or did not assess OS, TTP, or ORR.

A total of 3 trials (O'Shaughnessy et al. 2002; Pacilio et al. 2006; Sparano et al. 2009) were assessed in full text. Tables 1 and 2 outline the main characteristics of interventions and outcomes of included randomized clinical trials. The trials were published between 2002 and 2009 and carried out in USA and Italy.

All the selected studies enrolled patients pretreated with anthracyclines in different settings (i.e., adjuvant, neoadjuvant, or metastatic). O'Shaughnessy et al. (2002) report significantly superior TTP and OS achieved with the addition of capecitabine to docetaxel in 511 patients progressing after anthracycline treatment either in the (neo) adjuvant or the metastatic setting. Two studies enrolled patients treated with anthracyclines in the adjuvant-neoadjuvant setting, with docetaxel administered as first- or second-line therapy for the metastatic disease. Pacilio et al. (2006) randomized 51 metastatic breast cancer patients, pretreated with adjuvant-neoadjuvant epirubicin, to docetaxel plus epirubicin versus docetaxel alone as first-line

Table 1 Characteristics of interventions of selected clinical trials

\begin{tabular}{|c|c|c|c|}
\hline Features & O'Shaughnessy et al. (2002) & Pacilio et al. (2006) & Sparano et al. (2009) \\
\hline Country & USA & Italy & USA \\
\hline Study design & Randomized & Randomized & Randomized \\
\hline Primary end point & TTP & ORR & TTP \\
\hline $\begin{array}{l}\text { Secondary end } \\
\text { points }\end{array}$ & OS, ORR & OS, TTP & OS, ORR \\
\hline Treatment & $\begin{array}{l}\text { Capecitabine } 1,250 \mathrm{mg} / \mathrm{m}^{2} \\
\text { twice daily on days } 1 \text { to } 14 \\
\text { and docetaxel } 75 \mathrm{mg} / \mathrm{m}^{2} \text { on day } 1 \\
\text { or } \\
\text { docetaxel } 100 \mathrm{mg} / \mathrm{m}^{2} \text { on day } 1 . \\
\text { Cycles repeated every } 21 \text { days. }\end{array}$ & $\begin{array}{l}\text { Epirubicin } 75 \mathrm{mg} / \mathrm{m}^{2} \text { and } \\
\text { docetaxel } 80 \mathrm{mg} / \mathrm{m}^{2} \\
\text { or } \\
\text { docetaxel } 100 \mathrm{mg} / \mathrm{m}^{2} \\
\text { on day } 1 . \\
\text { Cycles repeated every } \\
21 \text { days. }\end{array}$ & $\begin{array}{l}\text { Pegylated liposomal doxorubicin } \\
30 \mathrm{mg} / \mathrm{m}^{2} \text { and docetaxel } \\
60 \mathrm{mg} / \mathrm{m}^{2} \\
\text { on day } 1 \\
\text { or } \\
\text { docetaxel } 75 \mathrm{mg} / \mathrm{m}^{2} \\
\text { on day } 1 . \\
\text { Cycles repeated every } 21 \text { days. }\end{array}$ \\
\hline Setting & $\begin{array}{l}\text { Anthracycline-pretreated metastatic breast } \\
\text { cancer }\end{array}$ & $\begin{array}{l}\text { Anthracycline pretreated in } \\
\text { the neoadjuvant/adjuvant } \\
\text { setting. } \\
\text { No previous chemotherapy } \\
\text { for metastatic breast cancer }\end{array}$ & $\begin{array}{l}\text { Anthracycline pretreated } \\
\text { in the neoadjuvant/adjuvant } \\
\text { setting. } \\
\text { Prior hormonal treatment and/ } \\
\text { or one regimen of } \\
\text { chemotherapy for metastatic } \\
\text { disease were acceptable }\end{array}$ \\
\hline
\end{tabular}


Table 2 Outcomes in selected clinical trials

\begin{tabular}{|c|c|c|c|c|c|c|}
\hline \multirow[t]{2}{*}{ Features } & \multicolumn{2}{|c|}{ O’Shaughnessy et al. (2002) } & \multicolumn{2}{|c|}{ Pacilio et al. (2006) } & \multicolumn{2}{|c|}{ Sparano et al. (2009) } \\
\hline & Combo & Mono & Combo & Mono & Combo & Mono \\
\hline No. of patients & 255 & 256 & 26 & 25 & 373 & 378 \\
\hline OS, median (months) & 14.5 & 11.5 & 18.0 & 21.0 & 20.5 & 20.6 \\
\hline TTP, median (months) & 6.1 & 4.2 & 9.0 & 11.0 & 9.8 & 7.0 \\
\hline ORR (\%) & 42 & 30 & $72^{\mathrm{a}}$ & $79^{\mathrm{a}}$ & 35 & 26 \\
\hline Complete response (\%) & 5 & 4 & 16 & 25 & - & - \\
\hline Partial response $(\%)$ & - & - & 56 & 54 & - & - \\
\hline Stable disease $(\%)$ & 38 & 44 & 16 & 12 & - & - \\
\hline Progressive disease (\%) & 11 & 20 & 12 & 4 & - & - \\
\hline Not assessable (\%) & 10 & 6 & - & 4 & - & - \\
\hline
\end{tabular}

${ }^{\mathrm{a}}$ Not eligible $=4 \%$ of patients, ORR on $\%$ of eligible patients. Combo: combination arm with docetaxel; Mono: docetaxel single agent

therapy. The study indicates that the addition of epirubicin to docetaxel does not improve PFS and OS as compared to single-agent docetaxel, but a major limitation of these data is that enrollment has been stopped earlier than planned due to poor accrual (Pacilio et al. 2006). Sparano et al. (2009) enrolled MBC patients, previously treated with neoadjuvant-adjuvant anthracycline therapy. Prior hormonal treatment of advanced breast cancer and/or one regimen of chemotherapy for advanced metastatic disease, excluding anthracycline, paclitaxel, docetaxel, vinorelbine, or vinblastine, were accepted. Seven hundred and fifty-one patients were randomly assigned to receive either docetaxel alone or docetaxel plus pegylated liposomal doxorubicin (PLD). Treatment with PLD-docetaxel significantly improved TTP and ORR, but not OS (Sparano et al. 2009).

In total, these three trials enrolled 1,313 patients: 654 of them received docetaxel combinations and 659 docetaxel as a single agent.

\section{Quality assessment}

Based on current standards, the quality of the included studies was suboptimal. Allocation concealment was adequately described in two of the three studies (O'Shaughnessy et al. 2002; Pacilio et al. 2006) and unclear in the remainder (Sparano et al. 2009).

All the studies adequately described blinding of outcome assessors and the others domains. One of these was interrupted earlier (Pacilio et al. 2006).

\section{Clinical outcomes}

No significant benefit in OS was found with a chemotherapy agent plus docetaxel compared with docetaxel alone (RR: 0.92, 0.73-1.16; $P=0.48$ ). Heterogeneity among the studies in this analysis was moderate $\left(Q=4.68 ; P=0.096 ; I^{2}=57.24 \%\right.$; Fig. 1$)$.
A significant reduction in risk ratio was found in TTP with chemotherapy agent plus docetaxel compared with docetaxel alone (RR: 0.66, 0.58-0.74; $P=<0.0001$ ). Heterogeneity was not significant among studies in this analysis $\left(Q=1.46 ; P=0.48 ; I^{2}=0 \%\right.$; Fig. 1$)$.

Regarding ORR, polychemotherapy did not increase the probability of response (RR: $1.22,0.96-1.56 ; P=0.10$ ) as compared with docetaxel alone. Heterogeneity in this analysis was moderate $\left(Q=5.12 ; P=0.077 ; I^{2}=60.93 \%\right.$; Fig. 2).

Toxicity

Figure 3 presents the summary estimates of the toxicity of chemotherapy agent plus docetaxel compared with docetaxel alone. Results show that a treatment with docetaxel alone is associated with a lower incidence of grade 3 neutropenic fever, nausea, neutropenia, diarrhea, and stomatitis, although only for diarrhea and stomatitis, the results have statistical significance (diarrhea, RR: 2.51, 1.45-4.34; $P=0.011$; stomatitis, RR: 5.62, 2.16-14.63; $P=0.0004)$.

Heterogeneity among the studies in this analysis was not significant regarding diarrhea $\left(Q=0.70 ; P=0.70 ; I^{2}=\right.$ $0 \%)$, and moderate relative to stomatitis $(Q=3.66$; $\left.P=0.16 ; I^{2}=45.35 \%\right)$.

\section{Discussion}

The efficacy of docetaxel in MBC has been mostly established in randomized phase III trials (Chan et al. 1999; Nabholtz et al. 1999, 2003; Mackey et al. 2002) designed to test chemotherapy with docetaxel versus chemotherapy without docetaxel. This is the first meta-analysis of prospective studies (O'Shaughnessy et al. 2002; Pacilio et al. 2006; Sparano et al. 2009) addressing the question of whether the addition of chemotherapy agents to single- 
Fig. 1 Overall survival and time to tumor progression risk ratios

Fig. 2 Overall response rate risk ratios

\section{Overall Survival} Study

Risk

Ratio

Confidence Interval (95\%)

O'Shaughnessy et al.,

0.78

0.63-0.95 2002

Pacilio et al, 2006

1.17

$0.61-2.22$

Sparano et al, 2009

1.02

$0.86-1.22$

Total

0.92

0.73-1.16 ( $P=0.4833)$

Heterogeneity: $Q=4.68 ; d f=2 ;(p=0.096) ; I^{* 2}=57.24$

\section{Time Tumor Progression}

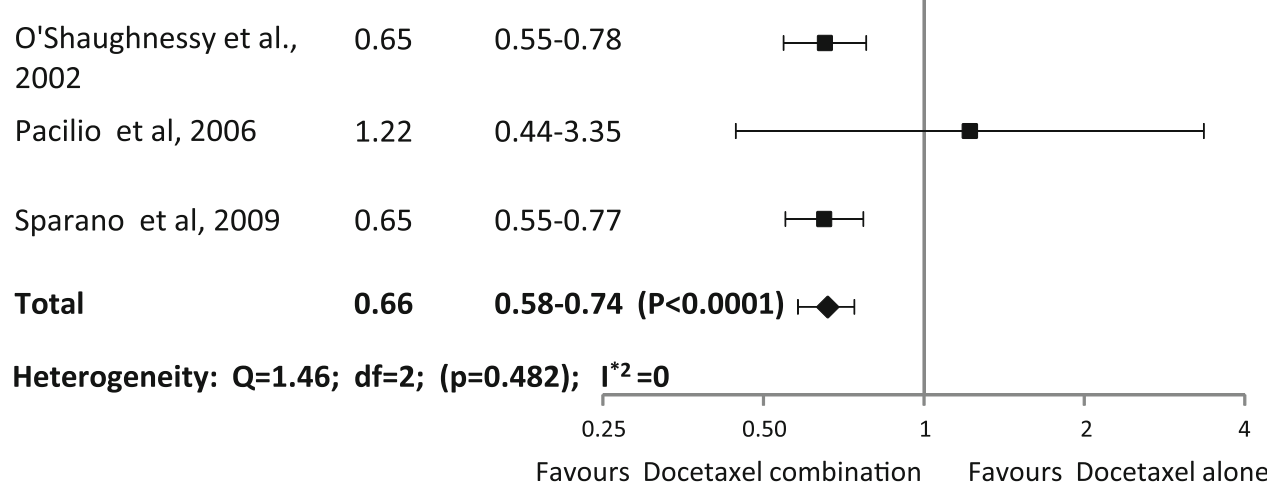

Overall response rate Study

Risk

Ratio

O'Shaughnessy et al., $\quad 1.40$ 2002

Pacilio et al, 2006

0.91

$0.66-1.25$

Confidence
Interval $(95 \%)$

$1.11-1.77$

Risk Ratio

(95\% Cl)

Interval (95\%)

$1.08-1.68$

Sparanoet al, $2009 \quad 1.35$

Total

1.22

0.96-1.56 $(P=0.1046)$

Heterogeneity: $Q=5.12 ; d f=2 ;(p=0.077) ; I^{* 2}=60.93$

0.5

Favours Docetaxel alone
(95\% Cl)

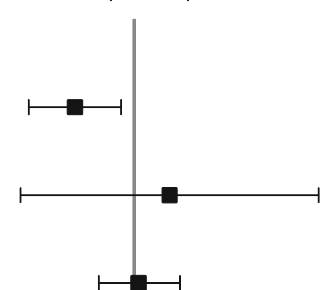

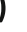

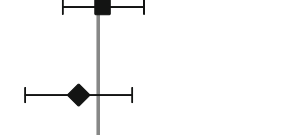


Fig. 3 G3 and G4 toxicity risk ratio

$\begin{array}{lll}\text { Study } & \begin{array}{c}\text { Risk } \\ \text { Ratio }\end{array} & \begin{array}{c}\text { Confidence } \\ \text { Interval(95\%) }\end{array} \\ \text { Fatigue (Grade 3) } & & \\ \text { O'Shaughnessy, 2002 } & 0.73 & 0.41-1.29 \\ \text { Pacilio, 2006 } & 2.89 & 0.12-67.57 \\ \text { Sparano, 2009 } & 1.50 & 0.60-3.74 \quad \\ \text { Overall } & 1 & \mathbf{0 . 5 1 - 1 . 9 4 \quad ( p = 0 . 9 9 9 6 )}\end{array}$

Heterogeneity: $Q=2.22 ; d f=2 ;(p=0.3288) ; I^{* 2}=10.09$

Neutropenic fever (Grade 3)

\begin{tabular}{|c|c|c|}
\hline O'Shaughnessy, 2002 & 0.60 & $0.24-1.52$ \\
\hline Pacilio, 2006 & 3 & $0.34-26.66$ \\
\hline $\begin{array}{l}\text { Sparano, } 2009 \\
\text { Overall }\end{array}$ & $\begin{array}{l}8.90 \\
1.64\end{array}$ & $\begin{array}{l}0.48-163.93 \\
0.33-8.15 \quad(p=0.5432)\end{array}$ \\
\hline
\end{tabular}

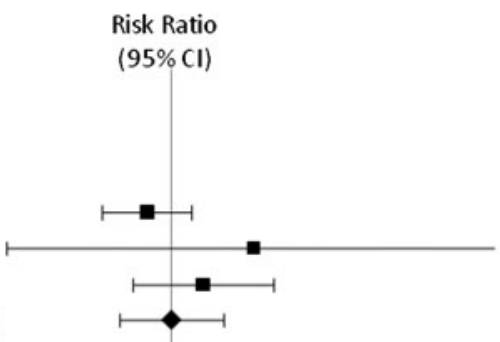

Nausea (Grade 3)

\begin{tabular}{|c|c|c|}
\hline O'Shaughnessy, 2002 & 3 & $1.09-8.23$ \\
\hline Pacilio, 2006 & 2.89 & $0.12-67.56$ \\
\hline Sparano, 2009 & 1 & $0.24-4.15$ \\
\hline Overall & 2.07 & $0.86-5.00 \quad(p=0.1048)$ \\
\hline
\end{tabular}

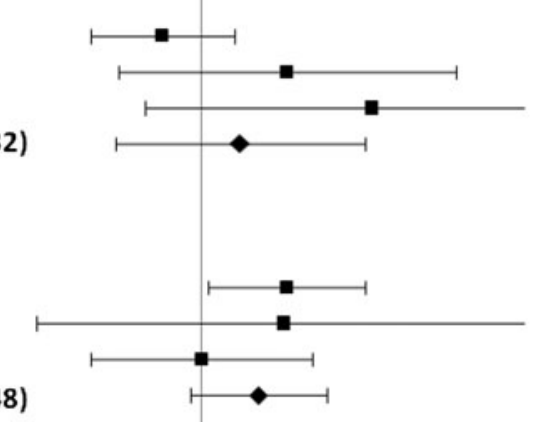

Neutropenia (Grade 3)

O'Shaughnessy, 2002

Pacilio, 2006

Sparano, 2009

Overall

1.67

$0.67-4.14$

0.50

1.17

1.18

$0.10-2.43$

$0.87-1.56$

Heterogeneity: $Q=1.68 ; \mathrm{df}=2 ;(p=0.4328) ; I^{* 2}=0$

\section{Neutropenia (Grade 4)}

O'Shaughnessy, 2002

Pacilio, 2006

0.69

1.28

0.88

Sparano, 2009

0.93

$0.90-1.55 \mathrm{p}=0.2405$

Overall

$0.43-1.10$

$0.88-1.88$

$0.73-1.05$

$0.69-1.25 p=0.621$

Heterogeneity: $Q=4.57 ; d f=2 ;(p=0.1019) ; I^{* 2}=56.21$

Diarrhea (Grade 3)

O'Shaughnessy, 2002

Pacilio, 2006

Sparano, 2009

Overall

2.80

$\begin{array}{ll}2.80 & 1.49-5.25 \\ 1 & 0.07-14.73\end{array}$

2

2.51

$0.58-6.86$

Heterogeneity: $Q=0.70 ; d f=2 ;(p=0.7045) ; I^{* 2}=0$

Stomatitis (Grade 3)

O'Shaughnessy, 2002

Pacilio, 2006

Sparano, 2009

Overall

6.74

$1.85-6.26$

$0.37-123.46$

$3.85-31.43$

5.62

$2.16-14.63 p=0.0004$

Heterogeneity: $Q=3.66 ; d f=2 ;(p=0.1604) ;\left.\right|^{* 2}=45.35$

0.02

0.06
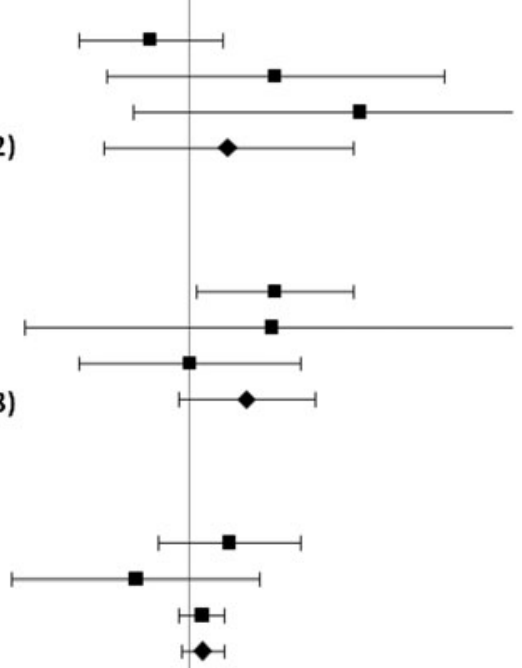

Favours Docetaxel combination agent docetaxel improves outcome in MBC. In our analysis, combination chemotherapy with docetaxel demonstrated a significant reduction in the risk of TTP as compared with docetaxel alone, but not a clear benefit in terms of either OS or ORR. The lack of significance in OS can be explained by the fact that all the studies were underpowered to detect a benefit in survival, even if
O'Shaughnessy et al. (2002) found a significant advantage in favor of the combination arm. Also, the absence of a significant benefit for polychemotherapy in terms of ORR may be attributed to the limited number of patients included in the study by Pacilio et al. (2006), which was early terminated due to poor accrual and accounts for most of the observed heterogeneity. 
Heterogeneity among trials was also related to different schedules, selection of patients, and line of treatment. Docetaxel in monotherapy was used at the dose of $100 \mathrm{mg} / \mathrm{m}^{2}$ by O'Shaughnessy et al. (2002) and by Pacilio et al. (2006), and at the dose of $75 \mathrm{mg} / \mathrm{m}^{2}$ by Sparano et al. (2009), always administered at day 1 with cycles repeated every 21 days. All enrolled patients have been previously treated with anthracyclines, either in the metastatic setting (O'Shaughnessy et al. 2002) or in the neoadjuvant/adjuvant setting (Pacilio et al. 2006; Sparano et al. 2009). Only the study by Pacilio et al. enrolled patients who did not have previous chemotherapy for metastatic breast cancer, while for O'Shaughnessy et al. (2002), patients with breast cancer in progression during/after anthracycline treatment for metastatic disease or relapsing within 2 years of completing (neo) adjuvant anthracyclinebased chemotherapy, were eligible. In the study by Sparano et al. (2009), prior hormonal treatment of advanced breast cancer and/or one regimen of chemotherapy for advanced metastatic disease were acceptable, but treatment of the advanced disease with an anthracycline, paclitaxel, docetaxel, vinorelbine, or vinblastine was not allowed. In two studies, docetaxel was used in combination with anthracyclines, epirubicin (Pacilio et al. 2006), or pegylated liposomal doxorubicin (Sparano et al. 2009), and in the last study in combination with the oral fluoropyrimidine capecitabine (O'Shaughnessy et al. 2002).

No significant difference between docetaxel in combination therapy versus single-agent docetaxel has been found in the evaluable patient population for toxic effects such as fatigue, nausea, neutropenic fever, and neutropenia. Only grade 3 diarrhea and stomatitis had a higher statistical incidence in the combination arms.

Our data confirm results obtained by Xu et al. (2011), who explored through a literature-based meta-analysis whether taxane-based doublets improve outcome over single-agent taxane in patients with MBC. They show that docetaxel- or paclitaxel-based doublets appear to improve PFS, but not OS and ORR with grade 3-4 stomatitis and diarrhea, significantly higher in taxane-based doublets. Even if OS has also been shown to be an elusive end point and questioned, since it may be influenced by imbalance in use of active second-line therapies, by frequent cross-over to the investigational agent(s), and by the fact that many randomized trials are underpowered to detect OS differences, a formal validation of PFS or TTP as a surrogate for OS has so far been unsuccessful in MBC (Saad et al. 2010; Di Leo et al. 2004; Burzykowski et al. 2008).

Our meta-analysis shows that with available data from randomized clinical trial, we are still unable to clearly set the role of docetaxel in the treatment of $\mathrm{MBC}$, thus the single drug versus combination regimens controversy still persists. The strength of this investigation is that it represents a comprehensive review, based on a predefined study protocol and rigid inclusion criteria for randomized trials only. The main weakness is represented by the paucity of high-quality randomized trials testing this issue, and it is not based on individual patient data. In addition, heterogeneity between trials was found in some analyses, and causes of heterogeneity could not be explored owing to the scarcity of data.

In conclusion, combination chemotherapy regimens with docetaxel versus single-agent docetaxel show a statistically significant advantage for TTP, but not for OS and ORR in women with MBC, but they also produce more toxicity in terms of diarrhea and stomatitis. The results and limitations of this review confirm that it seems unlikely that any single agent or combination regimen will emerge as superior in all patients with MBC, most probably due to the highly heterogeneous nature of this disease (Perou et al. 2000; Sorlie et al. 2001; Wirapati et al. 2008).

Conflict of interest None of the authors has any potential financial conflict of interest related to this manuscript.

Open Access This article is distributed under the terms of the Creative Commons Attribution Noncommercial License which permits any noncommercial use, distribution, and reproduction in any medium, provided the original author(s) and source are credited.

\section{References}

Ardavanis A, Kountourakis P, Kyriakou F, Malliou S, Mantzaris I, Garoufali A, Yiotis I, Scorilas A, Baziotis N, Rigatos G (2008) Trastuzumab plus paclitaxel or docetaxel in HER-2-negative/ HER-2 ECD-positive anthracycline- and taxane-refractory advanced breast cancer. Oncologist 13(4):361-369. doi:10.1634/ theoncologist.2007-0207

Beslija S, Bonneterre J, Burstein HJ, Cocquyt V, Gnant M, Heinemann V, Jassem J, Kostler WJ, Krainer M, Menard S, Petit T, Petruzelka L, Possinger K, Schmid P, Stadtmauer E, Stockler M, Van Belle S, Vogel C, Wilcken N, Wiltschke C, Zielinski CC, Zwierzina H (2009) Third consensus on medical treatment of metastatic breast cancer. Ann Oncol 20(11):17711785. doi:10.1093/annonc/mdp261

Brewster AM, Hortobagyi GN, Broglio KR, Kau SW, Santa-Maria CA, Arun B, Buzdar AU, Booser DJ, Valero V, Bondy M, Esteva FJ (2008) Residual risk of breast cancer recurrence 5 years after adjuvant therapy. J Natl Cancer Inst 100(16):1179_ 1183. doi:10.1093/jnci/djn233

Burstein HJ, Keshaviah A, Baron AD, Hart RD, Lambert-Falls R, Marcom PK, Gelman R, Winer EP (2007) Trastuzumab plus vinorelbine or taxane chemotherapy for HER2-overexpressing metastatic breast cancer: the trastuzumab and vinorelbine or taxane study. Cancer 110(5):965-972. doi:10.1002/cncr.22885

Burzykowski T, Buyse M, Piccart-Gebhart MJ, Sledge G, Carmichael J, Luck HJ, Mackey JR, Nabholtz JM, Paridaens R, Biganzoli L, Jassem J, Bontenbal M, Bonneterre J, Chan S, Basaran GA, Therasse P (2008) Evaluation of tumor response, disease control, progression-free survival, and time to progression as potential surrogate end points in metastatic breast cancer. J Clin Oncol 26(12):1987-1992. doi:10.1200/jco.2007.10.8407 
Butters DJ, Ghersi D, Wilcken N, Kirk SJ, Mallon PT (2010) Addition of drug/s to a chemotherapy regimen for metastatic breast cancer. Cochrane Database Syst Rev 11:CD003368. doi: 10.1002/14651858.CD003368.pub3

Cardoso F, Bedard PL, Winer EP, Pagani O, Senkus-Konefka E, Fallowfield LJ, Kyriakides S, Costa A, Cufer T, Albain KS (2009) International guidelines for management of metastatic breast cancer: combination vs sequential single-agent chemotherapy. J Natl Cancer Inst 101(17):1174-1181. doi:10.1093/jnci/ djp235

Cardoso F, Senkus-Konefka E, Fallowfield L, Costa A, Castiglione M (2010) Locally recurrent or metastatic breast cancer: ESMO clinical practice guidelines for diagnosis, treatment and followup. Ann Oncol 21(Suppl 5):15-19. doi:10.1093/annonc/mdq160

Carrick S, Parker S, Thornton CE, Ghersi D, Simes J, Wilcken N (2009) Single agent versus combination chemotherapy for metastatic breast cancer. Cochrane Database Syst Rev (2):CD003372. doi:10.1002/14651858.CD003372.pub3

Chan S, Friedrichs K, Noel D, Pinter T, Van Belle S, Vorobiof D, Duarte R, Gil Gil M, Bodrogi I, Murray E, Yelle L, von Minckwitz G, Korec S, Simmonds P, Buzzi F, Gonzalez Mancha R, Richardson G, Walpole E, Ronzoni M, Murawsky M, Alakl M, Riva A, Crown J (1999) Prospective randomized trial of docetaxel versus doxorubicin in patients with metastatic breast cancer. J Clin Oncol 17(8):2341-2354

Di Leo A, Buyse M, Bleiberg H (2004) Is overall survival a realistic primary end point in advanced colorectal cancer studies? A critical assessment based on four clinical trials comparing fluorouracil plus leucovorin with the same treatment combined either with oxaliplatin or with CPT-11. Ann Oncol 15(4):545-549

Egger M, Davey Smith G, Schneider M, Minder C (1997) Bias in meta-analysis detected by a simple, graphical test. BMJ 315(7109):629-634

Force. ESoOE-MT (2007) Metastatic breast cancer. Recommendations proposal from the European school of oncology (ESO)MBC task force. Breast 16(1):9-10

Ghersi D, Wilcken N, Simes J, Donoghue E (2005a) Taxane containing regimens for metastatic breast cancer. Cochrane Database Syst Rev (2):CD003366. doi:10.1002/14651858. CD003366.pub2

Ghersi D, Wilcken N, Simes RJ (2005b) A systematic review of taxane-containing regimens for metastatic breast cancer. Br J Cancer 93(3):293-301. doi:10.1038/sj.bjc.6602680

Higgins JP, Thompson SG, Deeks JJ, Altman DG (2003) Measuring inconsistency in meta-analyses. BMJ 327(7414):557-560. doi: 10.1136/bmj.327.7414.557

Jemal A, Center MM, DeSantis C, Ward EM (2010a) Global patterns of cancer incidence and mortality rates and trends. Cancer Epidemiol Biomarkers Prev 19(8):1893-1907. doi:10.1158/ 1055-9965.epi-10-0437

Jemal A, Siegel R, Xu J, Ward E (2010b) Cancer statistics, 2010. CA Cancer J Clin 60(5):277-300. doi:10.3322/caac.20073

Jones SE, Erban J, Overmoyer B, Budd GT, Hutchins L, Lower E, Laufman L, Sundaram S, Urba WJ, Pritchard KI, Mennel R, Richards D, Olsen S, Meyers ML, Ravdin PM (2005) Randomized phase III study of docetaxel compared with paclitaxel in metastatic breast cancer. J Clin Oncol 23(24):5542-5551. doi: 10.1200/jco.2005.02.027

Kostler WJ, Brodowicz T, Zielinski CC (2010) Re: International guidelines for management of metastatic breast cancer: combination vs sequential single-agent chemotherapy. J Natl Cancer Inst 102 (3):207; author reply 207-208. doi:10.1093/jnci/djp483

Lin YC, Chang HK, Chen JS, Wang HM, Yang TS, Liaw CC (2007) A phase II randomized study of two taxanes and cisplatin for metastatic breast cancer after anthracycline: a final analysis. Jpn J Clin Oncol 37(1):23-29. doi:10.1093/jjco/hyl124
Mackey JR, Paterson A, Dirix LY (2002) Final results of the phase III randomized trial comparing docetaxel (T), doxorubicin (A) and cyclophosphamide (C) to FAC as first line chemotherapy for patients with metastatic breast cancer [abstract 137]. Proc Am Soc Clin Oncol 21:35a

Mukai H, Takashima T, Hozumi Y, Watanabe T, Murakami S, Masuda N, Mitsuyama S, Ohmura T, Yajima T, Ohashi Y (2010) Randomized study of taxane versus TS-1 in women with metastatic or recurrent breast cancer (SELECT BC). Jpn J Clin Oncol 40(8):811-814. doi:10.1093/jjco/hyq054

Nabholtz JM, Senn HJ, Bezwoda WR, Melnychuk D, Deschenes L, Douma J, Vandenberg TA, Rapoport B, Rosso R, Trillet-Lenoir V, Drbal J, Molino A, Nortier JW, Richel DJ, Nagykalnai T, Siedlecki P, Wilking N, Genot JY, Hupperets PS, Pannuti F, Skarlos D, Tomiak EM, Murawsky M, Alakl M, Aapro M, et al. (1999) Prospective randomized trial of docetaxel versus mitomycin plus vinblastine in patients with metastatic breast cancer progressing despite previous anthracycline-containing chemotherapy. 304 Study Group. J Clin Oncol 17(5):1413-1424

Nabholtz JM, Falkson C, Campos D, Szanto J, Martin M, Chan S, Pienkowski T, Zaluski J, Pinter T, Krzakowski M, Vorobiof D, Leonard R, Kennedy I, Azli N, Murawsky M, Riva A, Pouillart P (2003) Docetaxel and doxorubicin compared with doxorubicin and cyclophosphamide as first-line chemotherapy for metastatic breast cancer: results of a randomized, multicenter, phase III trial. J Clin Oncol 21(6):968-975

O’Shaughnessy J, Miles D, Vukelja S, Moiseyenko V, Ayoub JP, Cervantes G, Fumoleau P, Jones S, Lui WY, Mauriac L, Twelves C, Van Hazel G, Verma S, Leonard R (2002) Superior survival with capecitabine plus docetaxel combination therapy in anthracycline-pretreated patients with advanced breast cancer: phase III trial results. J Clin Oncol 20(12):2812-2823

Pacilio C, Morabito A, Nuzzo F, Gravina A, Labonia V, Landi G, Rossi E, De Maio E, Di Maio M, D’Aiuto G, Botti G, Normanno N, Chiodini P, Gallo C, Perrone F, de Matteis A (2006) Is epirubicin effective in first-line chemotherapy of metastatic breast cancer (MBC) after an epirubicin-containing adjuvant treatment? A single centre phase III trial. $\mathrm{Br} \mathrm{J}$ Cancer 94(9):1233-1236. doi:10.1038/sj.bjc.6603096

Perou CM, Sorlie T, Eisen MB, van de Rijn M, Jeffrey SS, Rees CA, Pollack JR, Ross DT, Johnsen $\mathrm{H}$, Akslen LA, Fluge O, Pergamenschikov A, Williams C, Zhu SX, Lonning PE, Borresen-Dale AL, Brown PO, Botstein D (2000) Molecular portraits of human breast tumours. Nature 406(6797):747-752. doi:10.1038/35021093

Piccart-Gebhart MJ, Burzykowski T, Buyse M, Sledge G, Carmichael J, Luck HJ, Mackey JR, Nabholtz JM, Paridaens R, Biganzoli L, Jassem J, Bontenbal M, Bonneterre J, Chan S, Basaran GA, Therasse P (2008) Taxanes alone or in combination with anthracyclines as first-line therapy of patients with metastatic breast cancer. J Clin Oncol 26(12):1980-1986. doi:10.1200/jco. 2007.10.8399

Radaideh SM, Sledge GW (2008) Taxane versus taxane: is the duel at an end? A commentary on a phase-III trial of doxorubicin and docetaxel versus doxorubicin and paclitaxel in metastatic breast cancer: results of the ERASME 3 study. Breast Cancer Res Treat 111(2):203-208. doi:10.1007/s10549-007-9776-4

Rosati MS, Raimondi C, Baciarello G, Grassi P, Giovannoni S, Petrelli E, Basile ML, Girolami M, Di Seri M, Frati L (2011) Weekly combination of non-pegylated liposomal doxorubicin and taxane in first-line breast cancer: wALT trial (phase I-II). Ann Oncol 22(2):315-320. doi:10.1093/annonc/mdq392

Saad ED, Katz A, Hoff PM, Buyse M (2010) Progression-free survival as surrogate and as true end point: insights from the breast and colorectal cancer literature. Ann Oncol 21(1):7-12. doi:10.1093/annonc/mdp523 
Sorlie T, Perou CM, Tibshirani R, Aas T, Geisler S, Johnsen H, Hastie T, Eisen MB, van de Rijn M, Jeffrey SS, Thorsen T, Quist H, Matese JC, Brown PO, Botstein D, Eystein Lonning P, BorresenDale AL (2001) Gene expression patterns of breast carcinomas distinguish tumor subclasses with clinical implications. Proc Natl Acad Sci USA 98(19):10869-10874. doi:10.1073/pnas.191 367098

Sparano JA, Makhson AN, Semiglazov VF, Tjulandin SA, Balashova OI, Bondarenko IN, Bogdanova NV, Manikhas GM, Oliynychenko GP, Chatikhine VA, Zhuang SH, Xiu L, Yuan Z, Rackoff WR (2009) Pegylated liposomal doxorubicin plus docetaxel significantly improves time to progression without additive cardiotoxicity compared with docetaxel monotherapy in patients with advanced breast cancer previously treated with neoadjuvant-adjuvant anthracycline therapy: results from a randomized phase III study. J Clin Oncol 27(27):4522-4529. doi:10.1200/jco.2008.20.5013

van Houwelingen HC, Arends LR, Stijnen T (2002) Advanced methods in meta-analysis: multivariate approach and metaregression. Stat Med 21(4):589-624
Vu T, Ellard S, Speers CH, Taylor SC, de Lemos ML, Hu F, Kuik K, Olivotto IA (2008) Survival outcome and cost-effectiveness with docetaxel and paclitaxel in patients with metastatic breast cancer: a population-based evaluation. Ann Oncol 19(3):461464. doi:10.1093/annonc/mdm527

Wirapati P, Sotiriou C, Kunkel S, Farmer P, Pradervand S, HaibeKains B, Desmedt C, Ignatiadis M, Sengstag T, Schutz F, Goldstein DR, Piccart M, Delorenzi M (2008) Meta-analysis of gene expression profiles in breast cancer: toward a unified understanding of breast cancer subtyping and prognosis signatures. Breast Cancer Res 10(4):R65. doi:10.1186/bcr2124

Xu HB, Xu Q, Li L (2011) A literature-based meta-analysis taxanebased doublet versus single-agent taxane chemotherapy in patients with advanced breast cancer. J Cancer Res Clin Oncol 137(6):1005-1013. doi:10.1007/s00432-010-0967-8 